\title{
Effects of alkali solution on the dissolution kinetics and optimization processes of iron from Akwuke ore
}

\author{
Kingsley Amechi Ani* (D) and Chidubem Chukwuebuka Chukelu
}

\begin{abstract}
Background: The dissolution process kinetics and optimization of iron from Akwuke ore were investigated in this study. The effects of process parameters such as agitation rate and ore particle size on the dissolution process were also examined. The Akwuke ore was characterized employing the XRD, FT-IR, SEM, and UV-spectroscopy.

Results: The results from the rate constants indicated that the diffusion through the boundary layer process with $R^{2}>0.96$ was the rate-determining mechanism. The maximum iron dissolution rate of $83.2 \%$ was obtained at $45-\mu m$ particle size while $81.2 \%$ and $72.6 \%$ iron dissolution rates were obtained at 490 and $390 \mathrm{rpm}$ agitation rates, respectively. Silicon oxide, aluminum oxide, and iron oxide were present in Akwuke ore as indicated from the XRD analysis. The RSM predicted optimum value of the iron dissolution rate from the numerical optimization was experimentally validated to confirm the satisfactory performance of the quadratic model.
\end{abstract}

Conclusion: This study concludes and presents the potential extraction of iron from Akwuke ore, which will be of immense benefit in hydrometallurgical process.

Keywords: Akwuke ore, Kinetics, Dissolution rate, RSM, Numerical optimization

\section{Background}

Globally, the demand for iron is steadily on the increase, and this is because it is used in civil engineering constructions as an excellent reinforcement in building bridges and houses. Also, the utilization of iron in steel manufacturing has been reported. Iron as one of the most prevalent of all metals is also among the earth's crust abundant elements. Iron ores are embedded in minerals such as hematite, pyrite, and ilmenite in the form of iron (III) oxide (Olvera-Venegas et al. 2017). However, oxides in iron constitute impurities that require removal as it affects the commercial value of iron. Different hydrometallurgical extraction processes have been used to study the extraction processes of iron and other valuable metals of interest from their oxide bearing nature (Kokes et al., 2014). Recently, attention has

* Correspondence: anikingsley16@yahoo.com

Department of Chemical Engineering, Faculty of Engineering, Nnamdi Azikiwe University, Awka, Nigeria

\section{Springer Open}

been directed towards the use of acid or alkaline reagents in the dissolution process to extract valuable metals from their oxide nature. Previously, Nadeem et al. (2014) used formic acid as a dissolution reagent in the leaching studies of magnesite from magnesite ore. Olvera-Venegas et al. (2017) investigated iron dissolution from kaolin using bisulfate from sodium thiosulfate as a reducing agent and citric acid as a complexing agent. Also, in a study carried out by Seyed and Azizi (2018), lead and zinc were leached out from an Iranian low-grade oxide ore with maximum recoveries of $72.12 \%$ and $85.52 \%$, respectively. However, to the best of our knowledge, there are no studies on the alkaline dissolution process of iron from Akwuke ore, which is the focus of this study. Accordingly, the objective of this work is to examine the dissolution of iron from Akwuke ore using sodium hydroxide $(\mathrm{NaOH})$ as a dissolution reagent after the initial analysis of Akwuke ore confirmed the presence of iron in oxide form. The characterization

(c) The Author(s). 2020 Open Access This article is licensed under a Creative Commons Attribution 4.0 International License, which permits use, sharing, adaptation, distribution and reproduction in any medium or format, as long as you give appropriate credit to the original author(s) and the source, provide a link to the Creative Commons licence, and indicate if changes were made. The images or other third party material in this article are included in the article's Creative Commons licence, unless indicated otherwise in a credit line to the material. If material is not included in the article's Creative Commons licence and your intended use is not permitted by statutory regulation or exceeds the permitted use, you will need to obtain permission directly from the copyright holder. To view a copy of this licence, visit http://creativecommons.org/licenses/by/4.0/. 
of Akwuke ore and the effects of process parameters (agitation rate and ore particle size) that affected the iron dissolution process were investigated. Also, the dissolution kinetics and numerical optimization of the process parameters were evaluated.

\section{Methods}

\section{Raw material collection and preparation}

The Akwuke ore sample was obtained from the Akwuke community located in Enugu State Nigeria. The ore sample was crushed and dried after which it was sieved. The ore sample was homogenized after oven drying it at $100{ }^{\circ} \mathrm{C}$.

\section{Characterizations of Akwuke ore}

The various phases in the Akwuke ore were identified using Siemen D500 XRD. The XRD analysis was performed at a $1^{\circ}$ divergence slit between the $2 \Theta$ ranges of $20-70^{\circ}$ while maintaining the voltage at $35 \mathrm{kV}$. Phase and elements identification was made using the joint committee on powder diffraction standard (JCPDS) file number. The Fourier transform infrared (FTIR) analysis of the raw ore sample was analyzed using a SHIMADZU 8400s infrared spectrophotometer. The spectra pattern was observed in transmission mode with a resolution of $4 \mathrm{~cm}^{-1}$ in the range of 4000 to $350 \mathrm{~cm}^{-1}$. The ore sample was analyzed at three different particle sizes using SEM (ASPEX 3020) at $10 \mathrm{kV}$ to determine their surface morphological characteristics. The UV-VIS spectrophotometer (SHIMADZU UV-1900i) was used to examine the Akwuke ore at a wavelength between 200 and $1000 \mathrm{~nm}$.

\section{Dissolution procedure}

The dissolution process of Akwuke ore was examined in a $250-\mathrm{mL}$ beaker using $20 \mathrm{~g}$ of the ore sample. The beaker was heated on a hot plate which contained a magnetic stirrer for continuous mixing. The experiment was conducted at room temperature with $3 \mathrm{M}$ sodium hydroxide $(\mathrm{NaOH})$ concentration, which was prepared as the dissolution reagent and put into the beaker. At a constant solid to liquid ratio, $20 \mathrm{~g}$ of the ore sample at different particle sizes $(45-600 \mu \mathrm{m})$ was added into the beaker containing $\mathrm{NaOH}$. The solution was mixed at varying agitation rates (90-490rpm). After the specified time, agitation rate, and particle size, the samples were withdrawn from the beaker filtered and the liquid phase analyzed for iron content using the atomic absorption spectrophotometer (iCE 3000 series ThermoFisher scientific). The dissolution rate of iron from Akwuke ore was calculated following Seyed and Azizi (2018) and expressed in Eq. (1).

$$
R(\%)=\frac{C_{A} \times V}{C_{O} \times M} \times 100
$$

From Eq. (2), $R$ (\%) is the dissolution rate of Iron; $\mathrm{C}_{\mathrm{A}}$ $\left(\mathrm{gL}^{-1}\right)$ is the concentration of iron in the dissolution liquor; $V(\mathrm{~L})$ is the dissolution liquor volume; $\mathrm{C}_{\mathrm{o}}$ is the iron content in the oxide ore; and $M(\mathrm{~g})$ is the mass of the iron oxide.

\section{Statistical analysis}

The statistical method used in this study investigates the kinetic model validity by estimating the degree of correlation between the experimental and model calculated data. The correlation coefficient $\left(R^{2}\right)$ and the root mean square error (RSME) of Eqs. (2) and (3), respectively, were used to judge the degree of the model representation of experimental data (Kitanovic et al. 2008). The model goodness of fit to experimental data was evaluated using the lower values of RMSE and higher $R^{2}$ values (Kitanovic et al. 2008). From Eqs. (2) and (3), Xexp and Xcal are experimental and model calculated conversion values; $n$ is the number of data points.

$$
\begin{aligned}
& \mathrm{R} 2=1-\frac{\sum_{n=1}^{n}(\mathrm{Xexp}-\mathrm{Xcal})^{2}}{\sum_{n=1}^{n}(\mathrm{Xexp}-\mathrm{Xcal})^{2}} \\
& \operatorname{RMSE}(\%)=\sqrt{\frac{1}{\mathrm{n}} \sum_{n=}^{n}\left(\frac{\mathrm{Xexp}-\mathrm{Xcal}}{\mathrm{Xexp}}\right)^{2}}
\end{aligned}
$$

\section{Experimental design methodology}

The central composite design (CCD) of response surface methodology (RSM) with two categorical variables was employed to correlate and study the influence of the ore particle size and agitation rate on the dissolution rate (\%) of iron from Akwuke ore. The CCD methodology allows the investigation of a quadratic model for the response (\% dissolution rate). The quadratic model which correlates the relationship between the response $(\mathrm{Y})$ and the independent variables under investigation is presented in Eq. (4).

$$
\begin{aligned}
Y= & \beta o+\sum_{j=1} \beta i . x i+\sum_{j=1} \beta i i . x i^{2} \\
& +\sum_{i=1} \sum_{j=2} \beta i j . x i x j+e
\end{aligned}
$$

where $x i, x i^{2}$, and $x i x j$ are the linear, quadratic, and interactive terms of the quadratic model, respectively, while $e$ is the random error (Elibol, 2002). $\beta o, \beta i$, $\beta i i$, and, $\beta i j$ represent the intercept, coefficients of the linear, quadratic, and interactive terms, respectively, as shown 
in Eq. (4). The Design Expert (version 7.0, Stat Ease Inc. Minneapolis, USA) was used for statistical analysis. The statistical significance for the ANOVA of the quadratic model was investigated using the $p$ value, $F$ value, $R^{2}$, and the lack of fit test (Elibol, 2002). The levels and ranges of the independent variables in the CCD design are presented in Table 1. The experimental design matrix in terms of the actual values of the independent variables (ore particle size and agitation rate) with the corresponding actual and predicted responses is shown in Table 2 . The response surface plots generated from the significant model equation was used to study the interactive effects of the independent variables on the response (Ani and Ochin, 2018). Furthermore, a numerical optimization process was used to predict the optimum dissolution rate of iron from Akwuke ore, which was validated experimentally.

\section{Kinetics of iron dissolution from Akwuke ore}

The dissolution process of metals from ores of different types involves a heterogeneous solid to liquid reactions (Liddell, 2005). To understand the dissolution process kinetics, the shrinking core model, which was explained in detail by Liddell (2005) is widely used. However, the dissolution process of iron from Akwuke ore is a ratelimiting phenomenon. The rate-limiting mechanism of the iron dissolution process was investigated using the surface chemical reaction (Eq. (5)) and the diffusioncontrolled (Eq. (6)) processes of the shrinking core model (Liu et al. 2014; Das et al. 2015). The suitability of the shrinking core model emanates from the fact that it relates the conversion fraction $(\mathrm{X})$ of the ore solid particle to the reaction rate constant $(\mathrm{K})$ and reaction time (t) (Liu et al. 2014; Das et al. 2015).

$$
\begin{aligned}
& 1-(1-\mathrm{X})^{1 / 3}=\mathrm{K}_{\mathrm{s}} \cdot \mathrm{t} \\
& 1-\frac{2}{3} X-(1-X)^{\frac{2}{3}}=K_{d} \cdot \mathrm{t}
\end{aligned}
$$

The rate constant for the surface chemical reaction $\left(\mathrm{K}_{\mathrm{s}}\right)$ was obtained from the slope of the linear plot of 1 $-(1-X)^{1 / 3}$ versus time (t) using Eq. (5). Also, the rate constant for the diffusion process $\left(\mathrm{K}_{\mathrm{d}}\right)$ was obtained from the slope of the linear plot of $1-\frac{2}{3} X-(1-X)^{\frac{2}{3}}$ versus time (t) using Eq. (6). The obtained rate constants with their corresponding $R^{2}$ values were used to judge the rate-limiting mechanism that governs the dissolution

Table 1 Independent variables and levels

\begin{tabular}{llllll}
\hline Name & Unit & -1 level & +1 level & - alpha & + alpha \\
\hline Particle size & $\mu m$ & -45 & 600 & -69.94 & 714.94 \\
Agitation rate & rpm & -90 & 490 & -7.15 & 572.84 \\
\hline
\end{tabular}

Table 2 Experimental design matrix with responses

\begin{tabular}{lllll}
\hline Std. & $\begin{array}{l}\text { Particle } \\
\text { size } \\
(\mu \mathrm{m})\end{array}$ & $\begin{array}{l}\text { Agitation } \\
\text { rate } \\
(\mathrm{rpm})\end{array}$ & \multicolumn{2}{l}{ Responses } \\
\cline { 3 - 5 } & 45.00 & 90.00 & 78.02 & 73.84 \\
\hline 1 & 600.00 & 90.00 & 78.21 & 76.27 \\
2 & 45.00 & 490.00 & 72.08 & 72.49 \\
3 & 600.00 & 490.00 & 70.04 & 72.70 \\
4 & 69.94 & 290.00 & 69.03 & 71.38 \\
5 & 714.94 & 290.00 & 74.07 & 73.25 \\
6 & 45.00 & 7.16 & 73.06 & 77.07 \\
7 & 45.00 & 572.84 & 76.08 & 73.59 \\
8 & 45.00 & 290.00 & 84.99 & 86.26 \\
9 & 322.50 & 290.00 & 85.05 & 86.26 \\
10 & 322.50 & 290.00 & 86.11 & 86.26 \\
11 & 322.50 & 290.00 & 88.08 & 86.26 \\
12 & 322.50 & 290.00 & 87.09 & 86.26 \\
13 & & & &
\end{tabular}

process of iron from Akwuke ore. However, the ratelimiting mechanism was believed to be the slowest step between the surface chemical reaction and the diffusioncontrolled processes of the shrinking core model (Asim et al. 2013; Baba et al. 2014; Yi et al. 2014).

\section{Results}

\section{Effects of process parameters}

Effect of particle size and agitation rate on iron dissolution from Akwuke ore

The effects of ore particle sizes on iron dissolution rates from Akwuke ore was investigated at room temperature while varying the particle sizes from $45 \mu \mathrm{m}, 75 \mu \mathrm{m}, 150$ $\mu \mathrm{m}, 300 \mu \mathrm{m}$, and $600 \mu \mathrm{m}$. Other experimental conditions such as agitation rate and reaction time were kept constant at $490 \mathrm{rpm}$ and $240 \mathrm{~min}$, respectively. Experimental results in Fig. 1 showed that the iron dissolution rate from Akwuke

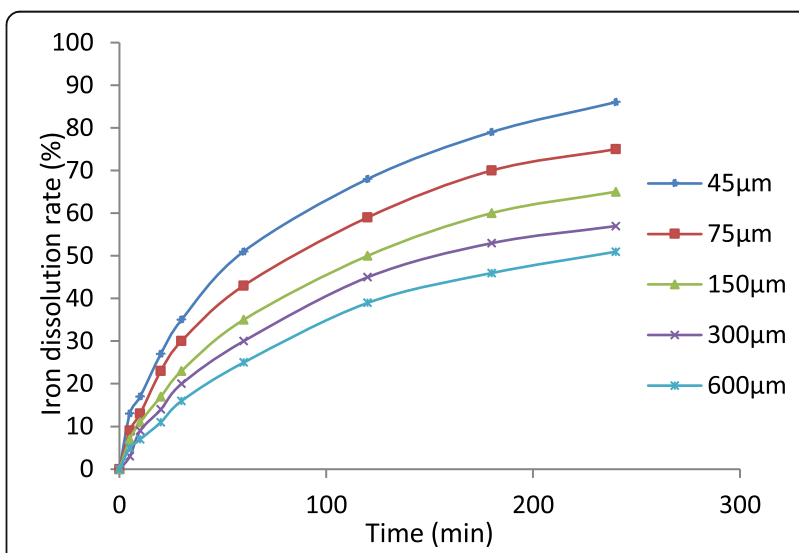

Fig. 1 Effects of ore particle sizes on the dissolution rate of iron from Akwuke ore 
ore increased from 78.4 to $83.2 \%$ at lower ore particle sizes of $75 \mu \mathrm{m}$ and $45 \mu \mathrm{m}$, respectively. The rate of iron dissolution from Akwuke ore was also found to have decreased at $150 \mu \mathrm{m}(62.1 \%), 300 \mu \mathrm{m}$ (57.2\%), and $600 \mu \mathrm{m}$ (43.3\%).

The effects of agitation rates on the dissolution rates of iron from Akwuke ore were examined at room temperature in the ranges of $90-490 \mathrm{rpm}$ under the following constant conditions of $45-\mu \mathrm{m}$ particle size and 240 min reaction time. Results showed that the dissolution rates of iron from Akwuke ore increased rapidly with an increase in agitation to the optimum rates of $72.6 \%$ and $81.2 \%$ at $390 \mathrm{rpm}$ and $490 \mathrm{rpm}$, respectively (Fig. 2). The result in Fig. 2 indicates that the dissolution rates at $90 \mathrm{rpm}, 190 \mathrm{rpm}$, and $290 \mathrm{rpm}$ were $41.1 \%$, $46.8 \%$, and $56.2 \%$, respectively.

\section{Kinetics of iron dissolution from Akwuke ore}

The rate constants for the surface chemical reaction process (Ks) as shown in Tables 3 and 4 were within the ranges of $0.0019-0.0025 \mathrm{~min}^{-1}$ and $0.0013-0.0022 \mathrm{~min}^{-1}$ for the agitation rate and ore particle size, respectively. Also, from Tables 3 and 4, the rate constants for the diffusion-controlled process $(\mathrm{Kd})$ were within the ranges of $0.0016-0.0021 \mathrm{~min}^{-1}$ and $0.0010-0.0020 \mathrm{~min}^{-1}$ for agitation rates and ore particle sizes, respectively. Observations made from the rate constants showed that the rate-determining mechanism governing the dissolution of iron from Akwuke ore favored the diffusioncontrolled process. The obtained $R^{2}$ values were also in support of the diffusion-controlled process as the ratedetermining mechanism. This was as the $R^{2}$ values for $\mathrm{Kd}$ were within the ranges of $0.995-0.998$, while for Ks it was within the ranges of $0.918-0.996$ (Tables 3 and 4). The experimental kinetic plots obtained at different agitation rates and ore particle sizes are presented in Figs. 3, 4, 5, and 6 .

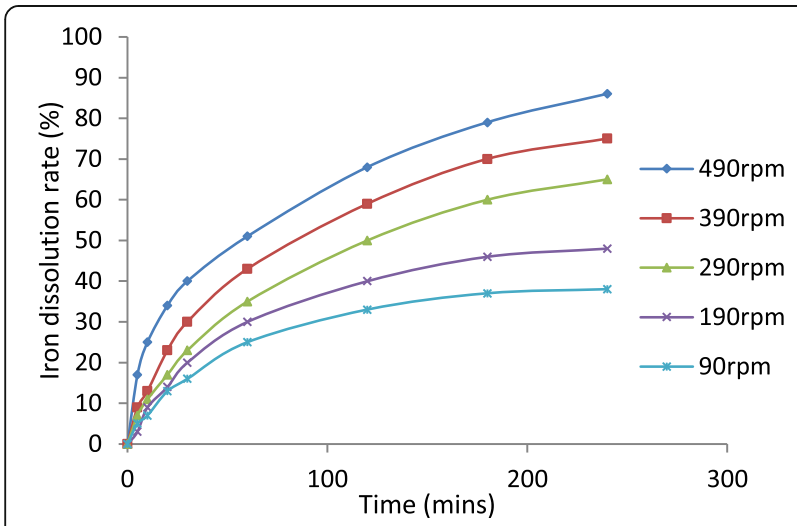

Fig. 2 Effects of agitation rates on the dissolution rate of Iron from Akwuke ore
Table 3 Rate constants and $R^{2}$ at different agitation rates

\begin{tabular}{llllll}
\hline \multirow{2}{*}{$\begin{array}{l}\text { Agitation } \\
\text { rates }(\mathrm{rpm})\end{array}$} & \multicolumn{2}{l}{ Surface chemical } & & \multicolumn{2}{l}{ Diffusion controlled } \\
\cline { 2 - 3 } & $\mathrm{Ks}\left(\mathrm{min}^{-1}\right)$ & $R^{2}$ & & $\mathrm{Kd}\left(\mathrm{min}^{-1}\right)$ & $R^{2}$ \\
\hline 90 & 0.0025 & 0.918 & & 0.0021 & 0.995 \\
190 & 0.0023 & 0.981 & & 0.0022 & 0.998 \\
290 & 0.0022 & 0.974 & 0.0020 & 0.987 \\
390 & 0.0018 & 0.973 & 0.0017 & 0.978 \\
490 & 0.0019 & 0.970 & 0.0016 & 0.976 \\
\hline
\end{tabular}

\section{Discussion}

\section{UV analysis of Akwuke ore}

The UV spectroscopy investigates the bonding structure and organic nature of the Akwuke ore. The peak ranges were from 200 to $1000 \mathrm{~nm}$ while four visible peaks were observed from the UV spectrum of Akwuke ore as shown in Fig. 7. The wavelength at maximum absorbance ( $(\mathrm{max})$ was observed at $253 \mathrm{~nm}$ and was indicative of the charge transition in montmorillonites which was within the ranges of 24-255 nm (Manoj and Kunjomana, 2011). The charge transition could be attributed to the migration of an electron to an oxo-ligand in the Akwuke ore. The saturated absorbance in some montmorillonites with divergent scattering might be responsible for the UV wavelength at $315 \mathrm{~nm}$ which shifted downwards to $538 \mathrm{~nm}$. The UV light absorbance in Akwuke ore reduced at a higher wavelength $(859 \mathrm{~nm})$ and might be due to a large conjugated system in the Akwuke ore, which tends to shift the peak towards a long wavelength (Fig. 7).

\section{XRD analyses of Akwuke ore}

The pattern of the XRD analysis of Akwuke ore in the $2 \Theta$ range at about $20-70^{\circ}$ is presented in Fig. 8. Accordingly, the elements in oxide form in Akwuke ore could also be seen in Fig. 8. These elements with their corresponding JCPDS file number includes Silicon oxide (420022), aluminum oxide (46-1215), iron oxide (40-1139), sphalerite (01-0792), and cassiterite (41-1445). The presence of iron oxide $\left(\mathrm{Fe}_{2} \mathrm{O}_{3}\right)$ indicated the possibility of leaching out this compound (iron) from Akwuke ore. The mineralogical composition of Akwuke ore also showed the presence of a siliceous mineral in the form of Silicon oxide otherwise known as quartz (Fig. 8). The

Table 4 Rate constant and $R^{2}$ at different ore particle sizes

\begin{tabular}{llllll}
\hline $\begin{array}{l}\text { Particle } \\
\text { sizes }(\mu \mathrm{m})\end{array}$ & \multicolumn{2}{l}{ Surface chemical } & & \multicolumn{2}{c}{ Diffusion controlled } \\
\cline { 2 - 3 } & $\mathrm{Ks}\left(\mathrm{min}^{-1}\right)$ & $R^{2}$ & & $\mathrm{Kd}\left(\mathrm{min}^{-1}\right)$ & $R^{2}$ \\
\hline 45 & 0.0013 & 0.994 & & 0.0010 & 0.997 \\
75 & 0.0014 & 0.995 & & 0.0013 & 0.998 \\
150 & 0.0018 & 0.995 & & 0.0015 & 0.998 \\
300 & 0.0019 & 0.995 & & 0.0017 & 0.998 \\
600 & 0.0022 & 0.996 & & 0.0020 & 0.998 \\
\hline
\end{tabular}




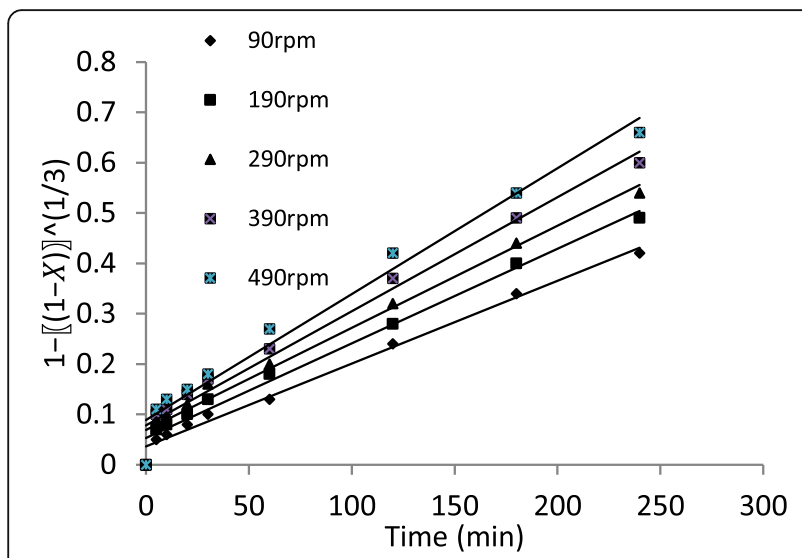

Fig. 3 Plot of $1-(1-X)^{1 / 3}$ versus dissolution time at different agitation rates

structural packing of the Akwuke ore layer arrangement was also investigated using the XRD analysis. Results deduced showed that silicon oxide and cassiterite existed in tetragonal sheet arrangements. Iron and sphalerite existed in the hexagonal sheet arrangements while aluminum oxide existed in the orthorhombic sheet arrangement.

\section{FTIR analysis of Akwuke ore}

Since the inorganic nature of the Akwuke ore is known to be embedded with metal oxides, the FTIR spectroscopy was used to study the functional groups of these metallic oxides. The FTIR spectrum of Akwuke ore is presented in Fig. 9, and it ranges from 3460 to $457 \mathrm{~cm}^{-1}$. The peak at the vicinity of $3460 \mathrm{~cm}^{-1}$ was indicative of the characteristics vibration of the $\mathrm{OH}$ stretching in silicates and water compounds. This vibration is similar to $3406.30 \mathrm{~cm}^{-1}$ observed from the FTIR spectrum analysis of azaraegbelu clay ore (Ohale et al. 2017) and was

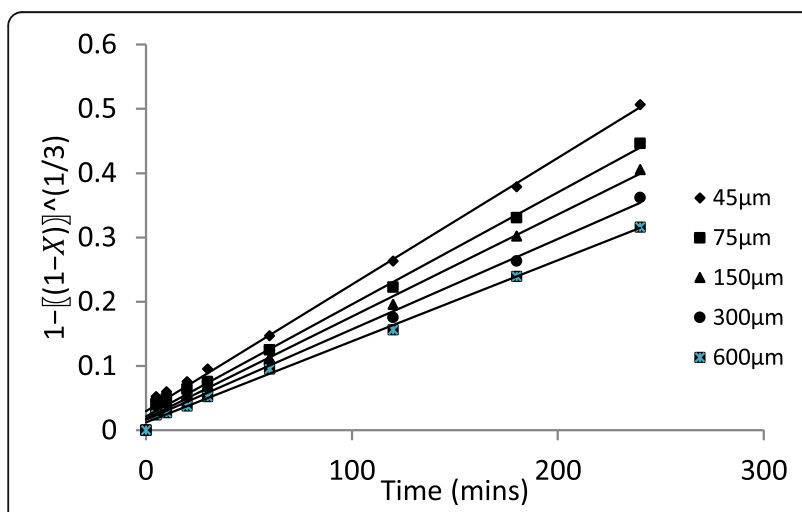

Fig. 4 Plot of $1-(1-X)^{1 / 3}$ versus dissolution time at different ore particle sizes

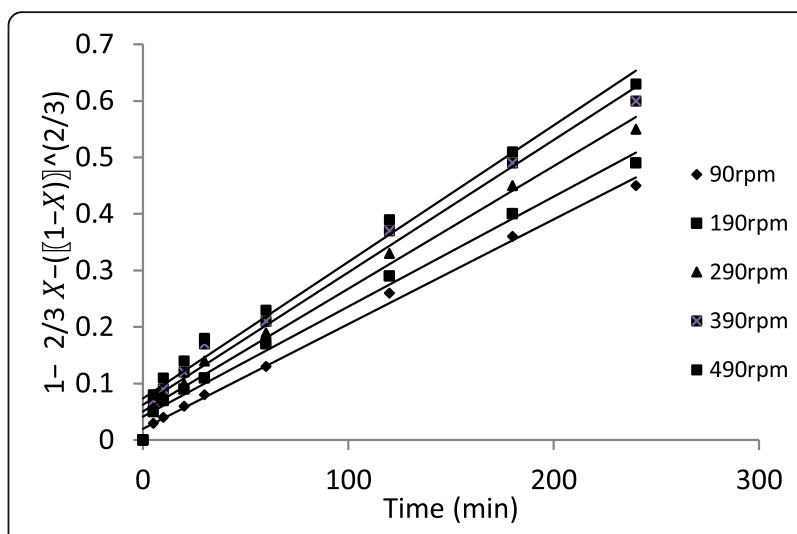

Fig. 5 Plot of $1-\frac{2}{3} X-(1-X)^{\frac{2}{3}}$ versus dissolution time at different agitation rates

attributed to the $\mathrm{OH}$ stretching in most silicates (Ohale et al. 2017). The band at $1583.93 \mathrm{~cm}^{-1}$ was due to the $\mathrm{CO}_{3}$ stretching of calcite, which was indicative of hectorite (Madejova and Komadel, 2001). The peak at 1098.36 $\mathrm{cm}^{-1}$ was assigned to the $\mathrm{Si}-\mathrm{O}$ stretching of cristobalite in montmorillonite. The $\mathrm{Si}-\mathrm{O}$ stretching vibration was observed at $801 \mathrm{~cm}^{-1}$ and was indicative of silica. Also, the $\mathrm{Si}-\mathrm{O}$ deformation of feldspar in palygorskite appeared at $457 \mathrm{~cm}^{-1}$ (Fig. 9).

\section{Scanning electron microscope (SEM)}

The surface morphologies of the investigated Akwuke ore at three different particle sizes are shown in Fig. 10. The micrographs were captured at $6 \mu \mathrm{m}, 20 \mu \mathrm{m}$, and 60 $\mu \mathrm{m}$. At $6 \mu \mathrm{m}$ in Fig. 10a, the micrograph shows a rough, porous, and spherical surface. The porous and rough surface could be due to the natural weathering process, which was intense in the area where the ore was located. There was no much difference between the $20 \mu \mathrm{m}$ and $60 \mu \mathrm{m}$ SEM micrographs (Figs. 10b, c) as both showed

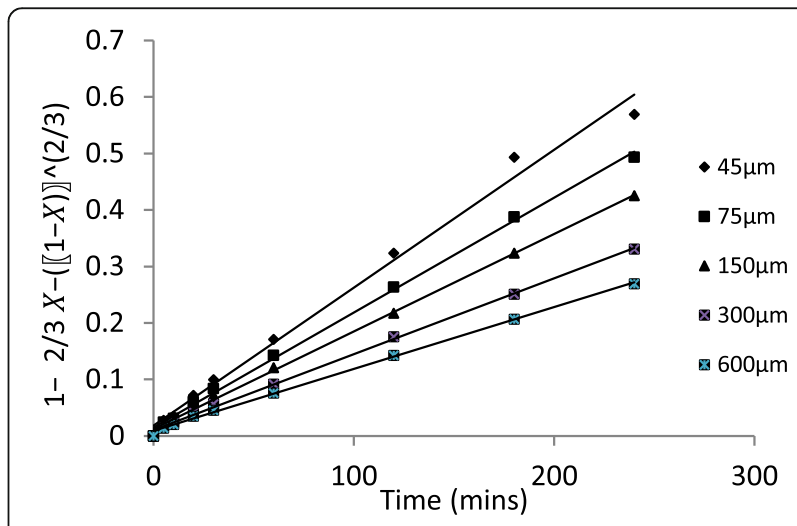

Fig. 6 Plot of $1-\frac{2}{3} X-(1-X)^{\frac{2}{3}}$ versus dissolution time at different ore particle sizes 


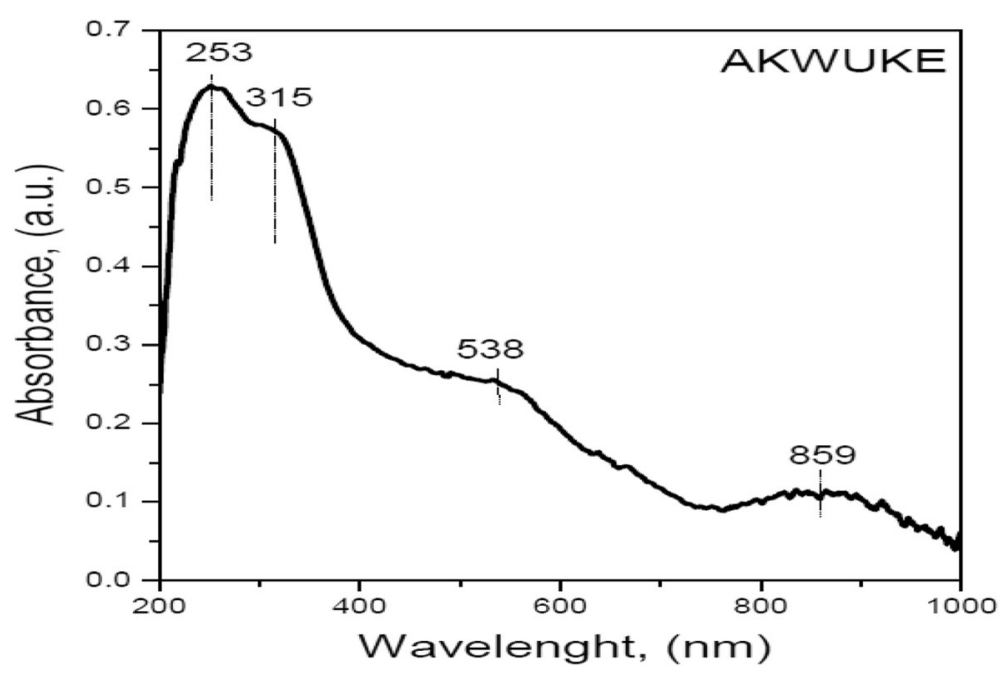

Fig. 7 UV-visible spectroscopy of Akwuke ore

filamentous and irregular edges, which was identical with hematite (Baioumy et al. 2013).

\section{Effect of particle size and agitation rate on iron} dissolution from Akwuke ore

The finer grind of ore particles produced at $45 \mu \mathrm{m}$ and $75 \mu \mathrm{m}$ may have allowed the alkali to penetrate the internal pores of the ore, contributing to an increase in the iron dissolution rate (Fig. 1). Also, previous studies reported that the finer ore particles produced at lower particle sizes provided an increased surface area to alkaline volume ratio, which enhanced the dissolution rate
(Nadeem et al. 2014; Madakkaruppan et al. 2016; Seyed and Azizi, 2018).

The observations made from the particle size effect further indicated that the coarse nature of the ore particles might not be suitable for the iron dissolution. The findings of this study indicated that increasing the ore particle size reduced the dissolution rate of iron from Akwuke ore and was in strong agreement with previous works on the dissolution process of metallic oxides from ores (Baba et al. 2012; Jianrong et al. 2016; Madakkaruppan et al. 2016; Adekola et al. 2018).

However, the $490 \mathrm{rpm}$ and $390 \mathrm{rpm}$ agitation rates might have permitted a homogenous mixing of the

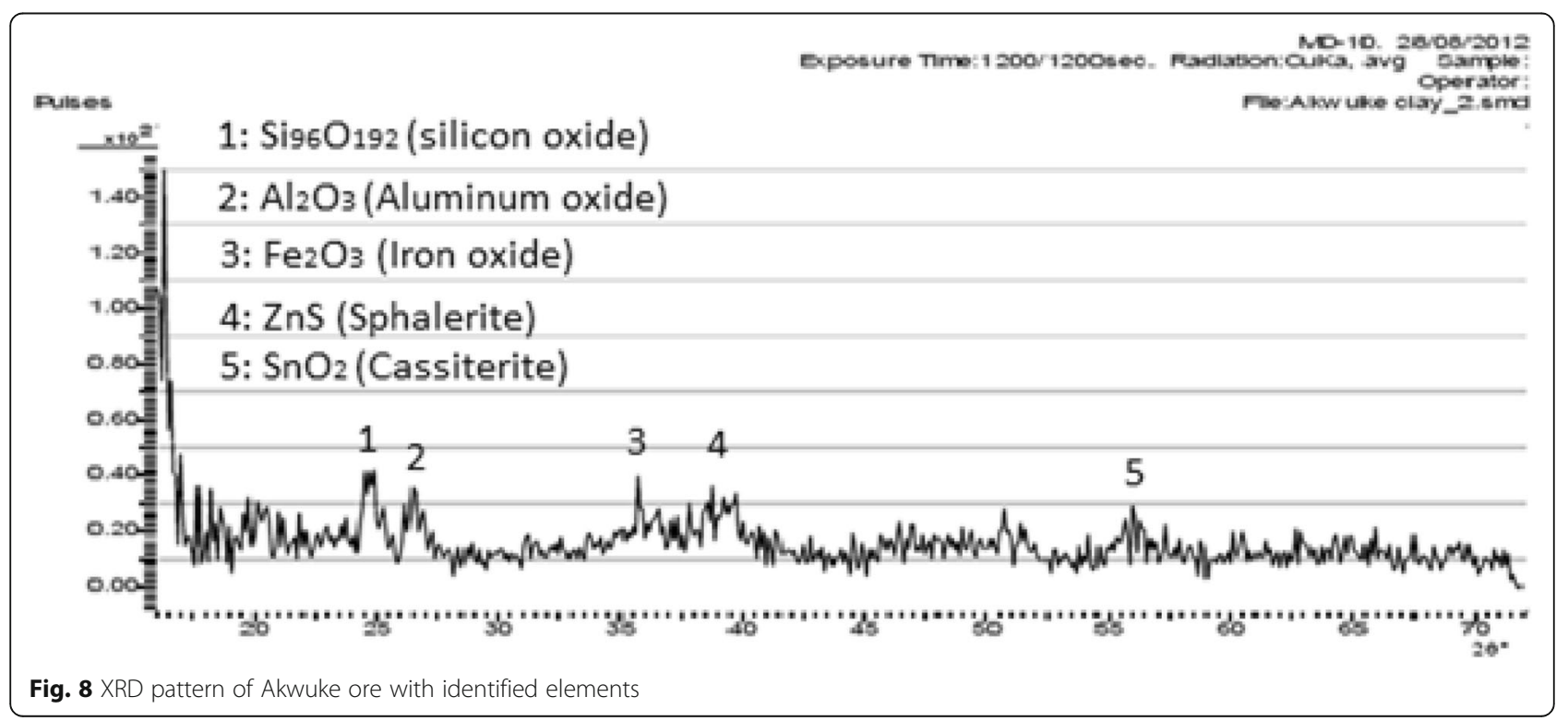



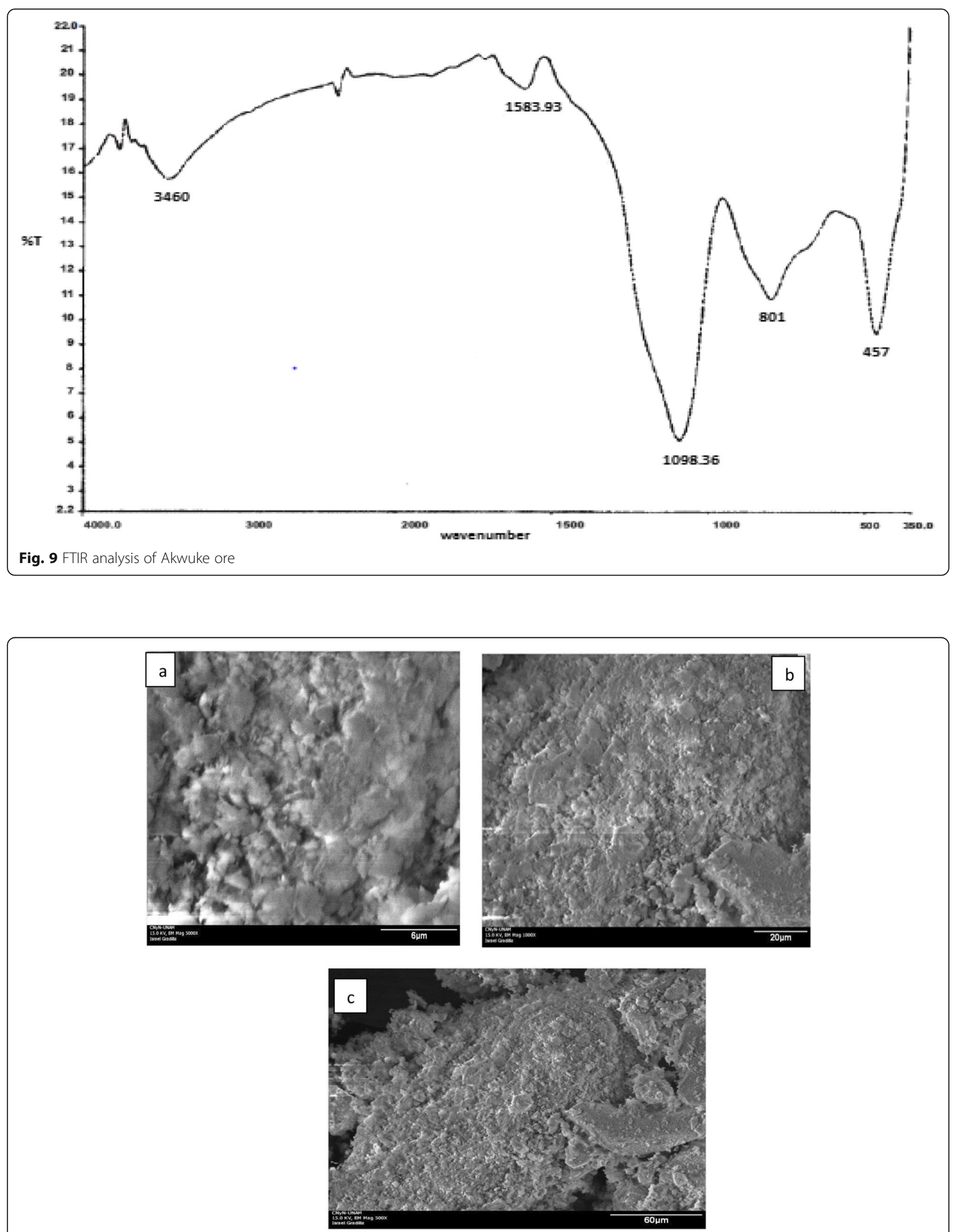

Fig. 10 a-c SEM analysis of Akwuke ore at particle sizes of a $6 \mu \mathrm{m}, \mathbf{b} 20 \mu \mathrm{m}$, and $\mathbf{c} 60 \mu \mathrm{m}$ 

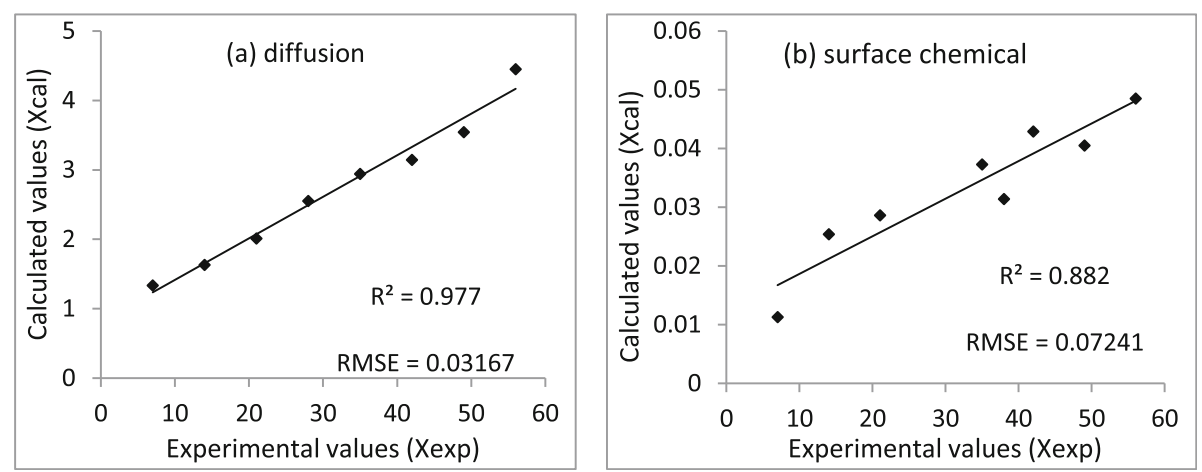

Fig. 11 a, b Correlations between experimental and calculated conversion values

alkaline solution with the reacting ore particles, which resulted in a higher dissolution rate (Fig. 2). Also, Madakkaruppan et al. (2015) reported that the increase in agitation rate enhances reagent diffusion to the surface of the reacting ore particle resulting in improved dissolution and process kinetics.

\section{Comparative fitness of the kinetic models}

The rate-determining mechanism between the surface chemical and diffusion-controlled processes of Eqs. (5) and (6), respectively, was further investigated. This was done by plotting the experimental conversion values (Xexp) and model calculated conversion values (Xcal) for both processes as shown in Fig. 11a, b. The degree of correlation between the experimental and calculated conversion values was judged from the $R^{2}$ values in Fig. 11a, b. It can be seen from Fig. 11a that the diffusion-controlled process gave a good correlation between the experimental and calculated conversion values with $R^{2}$ value of 0.977 when compared to the surface chemical process with $R^{2}$ value of 0.882 in Fig. 11b. Similarly, in the kinetics of chromium dissolution from Philippine chromite ore, Chen et al. (2013) reported that the diffusion process gave a better straight line with a relatively good fit $\left(R^{2}>\right.$ 0.98). The criteria for evaluating the fitness of the kinetic models to experimental data was also investigated using the RMSE tool. The RSME values for both the diffusion-controlled and surface chemical processes are shown in Fig. 11a, b. Observations made indicated that the RSME value for the diffusion-controlled process was less than $5 \%$ while it was greater than $5 \%$ for the surface chemical process. These results further validate the diffusion-controlled process as the rate-limiting and suitable mechanism for the iron dissolution process from Akwuke ore.

\section{Analysis of variance (ANOVA)}

Examining the ANOVA of the quadratic model in Table 5, it was found that the $p$ value of the model term AB was insignificant $(p>0.05)$. The insignificant term was removed from the model (Eq. (7)) to obtain a significant model equation (Eq. (8)) that contains only the significant variables (Ferdowsi and Yoozbashizadeh, 2017). The significant model of Eq. (8) was used to investigate the effects and interactions of the agitation rate and ore particle size on the rate of Iron dissolution. The model $p$ value of 0.0003 indicated the statistical significance of the quadratic model in predicting the iron dissolution rate (Table 5). The model with an $R^{2}$ value of 0.888 implies that $88.8 \%$ of the iron dissolution process was explained by the model. The $R^{2}$ value of 0.888 was also in good conformance with the predicted

Table 5 ANOVA for response surface quadratic model

\begin{tabular}{|c|c|c|c|c|c|c|}
\hline Source & $\begin{array}{l}\text { Sum of } \\
\text { Squares }\end{array}$ & df & $\begin{array}{l}\text { Mean } \\
\text { Square }\end{array}$ & $\boldsymbol{F}$ Value & $\begin{array}{l}\boldsymbol{p} \text { value } \\
\text { Prob }>\text { F }\end{array}$ & \\
\hline Model & 502.13 & 5 & 100.43 & 10.97 & 0.0003 & Significant \\
\hline A-Particle size & 3.48 & 1 & 3.48 & 0.38 & 0.0069 & \\
\hline $\begin{array}{l}\text { B-Agitation } \\
\text { rate }\end{array}$ & 12.1 & 1 & 12.1 & 1.32 & 0.008 & \\
\hline$A B$ & 1.24 & 1 & 1.24 & 0.14 & 0.724 & \\
\hline$A^{2}$ & 338.45 & 1 & 338.45 & 36.98 & 0.005 & \\
\hline$B^{2}$ & 207.77 & 1 & 207.77 & 22.7 & 0.002 & \\
\hline Residual & 64.07 & 7 & 9.15 & & & \\
\hline Lack of Fit & 56.97 & 3 & 18.99 & 10.7 & 0.22 & Non-significant \\
\hline Pure error & 7.1 & 4 & 1.78 & & & \\
\hline Cor total & 566.2 & 12 & & & & \\
\hline Std. Dev. & 3.03 & & $R^{2}$ & & & 0.888 \\
\hline Mean & 78.61 & & Adj $R^{2}$ & & & 0.806 \\
\hline C.V. \% & 3.85 & & Pred $R^{2}$ & & & 0.869 \\
\hline Press & 416.24 & & Adeq pr & recision & & 7.241 \\
\hline
\end{tabular}


and adjusted $R^{2}$ values of 0.869 and 0.806 , respectively (Table 5). The closeness of the $R^{2}$ values further indicated the suitability of the quadratic model in explaining the relationship between the rate of Iron dissolution and the independent variables of agitation rate and ore particle size (Ani and Ochin, 2018). The adequacy of the model was also confirmed through the mode lack-of-fit test. The model non-significant lack-of-fit (0.22) implies a good fit of the proposed model (Ani et al. 2018). The model adequate precision of 7.241 indicated a proper signal to noise ratio of the model as it was greater than 4 (Ferdowsi and Yoozbashizadeh, 2017; Zhang et al. 2010).

Model equation

$$
\begin{aligned}
(\%) \text { dissolution }= & +65.43001+0.063714 \mathrm{~A} \\
& +0.076334 \mathrm{~B}-1.00450 \mathrm{E} \\
& -005 \mathrm{AB}-9.05787 \mathrm{E}-005 \mathrm{~A}^{2} \\
& -1.36628 \mathrm{E}-004 \mathrm{~B}^{2}
\end{aligned}
$$

Significant model equation

$$
\begin{aligned}
(\%) \text { dissolution }= & +65.43001+0.063714 \mathrm{~A} \\
& +0.076334 \mathrm{~B}+9.05787 \mathrm{E}-005 \mathrm{~A}^{2} \\
& -1.36628 \mathrm{E}-004 \mathrm{~B}^{2}
\end{aligned}
$$

\section{Numerical optimization of the process variables}

The optimization process aims to predict the optimum values of the independent variables of the agitation rate and ore particle size. However, at the predicted optimized values, a maximum iron dissolution rate was achieved. The ranges of variables and goals with weight and importance were properly placed as shown in Table 6 . The optimization process using Design Expert 7.0 predicted the optimum agitation rate and particle size of $366.00 \mathrm{rpm}$ and $48.00 \mu \mathrm{m}$, respectively. At these optimized values, a maximum iron dissolution rate of $86.35 \%$ was obtained from Akwuke ore (Table 6). The optimized particle size value of $48.00 \mu \mathrm{m}$ was also in conformance with previous studies that reported that the reduction in ore particle size to a finer grain enhanced the dissolution process (Baba et al. 2012; Asim et al. 2013; Chen et al. 2013; Madakkaruppan et al. 2016). The optimized iron dissolution rate of $86.35 \%$ was further validated experimentally using the optimized values of $366.00 \mathrm{rpm}$ and $48.00 \mu \mathrm{m}$ for agitation rate and particle size, respectively. The result shows that the iron dissolution rate of $82.3 \%$ was obtained after the experimental validation. This value was close enough to the predicted value of $86.35 \%$, which confirmed the adequacy of the quadratic model.

\section{Diagnostic and response surface plots}

The confirmation of the model validity was evident as the normal probability plot in Fig. 12 shows a straight line. This indicates that the residual plots were properly aligned to the model fitted regression line. The interactive influences of the particle size and agitation rate on the iron dissolution from Akwuke ore were investigated. The significant model of Eq. (8) was used to construct the 2D contour and 3D response surface plots in Figs. 13 and 14. The lines of the 2D contour plot in Fig. 13 indicated a particular response (iron dissolution) obtained from the interactive effects of the ore particle size and agitation rate. The contour lines indicated that a maximum iron dissolution rate of $84.04 \%$ was obtained from Akwuke ore. Fig. 14 shows the 3D response surface plot of the iron dissolution process from Akwuke ore as a function of ore particle size and agitation rate. It was evident from the $3 \mathrm{D}$ surface plot that the increase in agitation rate and reducing the ore particle size gave a better iron dissolution result. This was as the surface curve increased towards the increase in agitation rate and decreased towards the ore particle

\begin{tabular}{|c|c|c|c|c|c|c|}
\hline \multirow[t]{2}{*}{ Name } & \multirow[t]{2}{*}{ Goal } & \multirow{2}{*}{$\begin{array}{l}\text { Lower } \\
\text { Limit }\end{array}$} & \multirow{2}{*}{$\begin{array}{l}\text { Upper } \\
\text { Limit }\end{array}$} & \multirow[t]{2}{*}{ Weight } & \multirow[t]{2}{*}{ Weight } & \multirow[t]{2}{*}{ Importance } \\
\hline & & & & & & \\
\hline Particle size & Is in range & 45 & 600 & 1 & 1 & 3 \\
\hline Agitation rate & Is in range & 90 & 490 & 1 & 1 & 3 \\
\hline (\%) dissolution & Maximize & 69.03 & 88.08 & 1 & 1 & 3 \\
\hline \multicolumn{7}{|l|}{ Solutions } \\
\hline Number & Particle size & Agitation rate & (\%) dissolution & Desirability & & \\
\hline 1 & 48.00 & 366.00 & 86.35 & 0.909 & Selected & \\
\hline
\end{tabular}
size (Fig. 14).

\section{Conclusion}

In this study, the iron dissolution process from Akwuke ore was investigated and the following conclusions were drawn.

Table 6 Numerical Optimized solutions and values for the quadratic model 

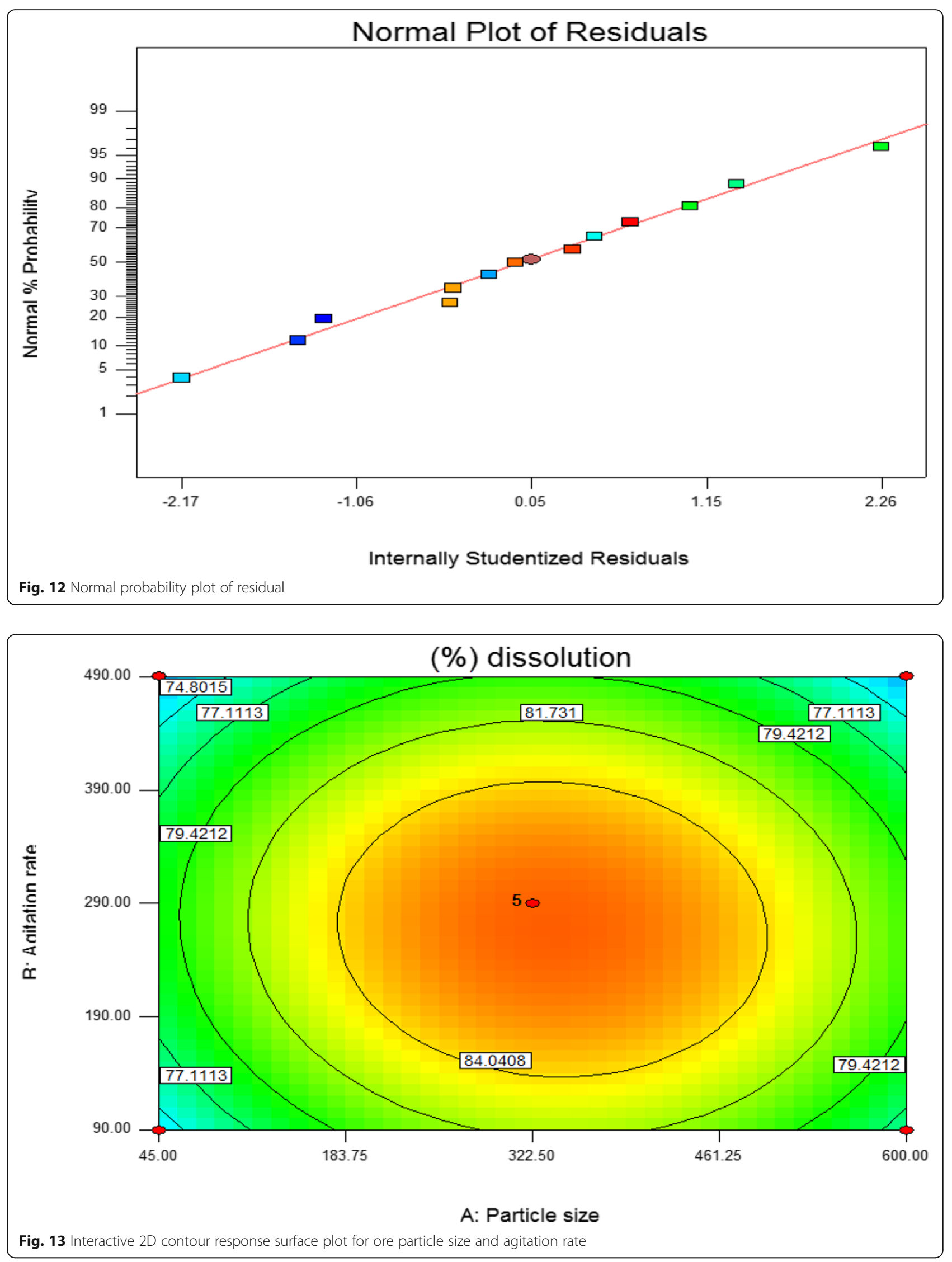


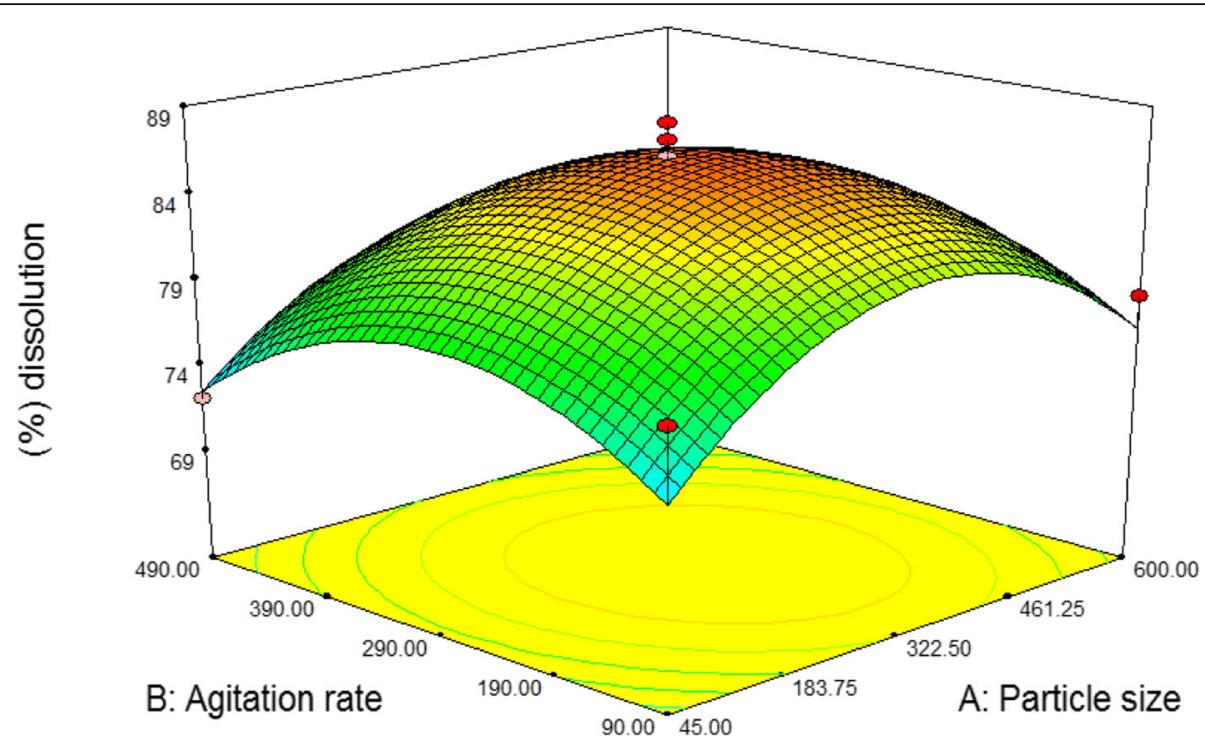

Fig. 14 Interactive 3D response surface plot for ore particle size and agitation rate

- The characterization of Akwuke ore by XRD showed the presence of iron oxide, silicon oxide, and aluminum oxide while the FTIR result indicated the presence of hectorite and montmorillonite.

- Under the process conditions of ore particle size of $45 \mu \mathrm{m}$ and agitation rate of $490 \mathrm{rpm}$, the dissolution rate of iron from Akwuke ore was $82.2 \%$ and $81.2 \%$, respectively.

- The kinetic analysis supported the diffusion process of the shrinking core model as the rate-determining mechanism governing the iron dissolution process from Akwuke ore.

- The quadratic model of the CCD was used to model the iron dissolution process while the numerical optimization process of the CCD predicted a maximum iron dissolution rate of $86.35 \%$ with agitation rate and ore particle size of $366.00 \mathrm{rpm}$ and $48 \mu \mathrm{m}$, respectively.

\section{Abbreviations}

UV-spectroscopy: Ultraviolet-visible spectroscopy; SEM: Scanning electron microscopy; FT-IR: Fourier transform infrared; XRD: X-ray diffraction; RSM: Response surface methodology; $\mathrm{NaOH}$ : Sodium hydroxide; CCD: Central composite design; RSME: Root mean square error; JCPDS: Joint Committee on Powder Diffraction Standards; ANOVA: Analysis of variance; $K_{s}$ : Surface chemical reaction rate constant; $K_{d}$ : Diffusion process rate constant

\section{Acknowledgements}

Not applicable

\section{Authors' contributions}

A.K.A analyzed and interpreted the data while C.C.C wrote and designed the manuscript. Both authors contributed in proofreading the manuscript. The authors read and approved the final manuscript.

\section{Funding}

Not applicable

\section{Availability of data and materials}

The datasets used and/or analyzed during the current study are available from the corresponding author on reasonable request.

Ethics approval and consent to participate

Not applicable

Consent for publication

Not applicable

\section{Competing interests}

The authors declare that they have no competing interests

Received: 31 March 2020 Accepted: 25 August 2020

Published online: 07 September 2020

\section{References}

Adekola FA, Olosho Al, Baba AA, Adebayo SA (2018) Dissolution kinetics of Nigerian gypsum ore in hydrochloric acid. J Chem Technol and Metall 53: 845-855

Ani AK, Ezeugwu F, Ochin E (2018) Growth and optimization process of mixed microbial population degrading chrysene. Gazi Uni J Sci 31(3):740-757

Ani KA, \& Ochin, E (2018) Response surface optimization and effects of agricultural wastes on total petroleum hydrocarbon degradation, Beni-Suef Uni. J Basic Appl Sci, 7, 564 - 574 https://doi.org/10.1016/j.bjbas.2018.06.009

Asim K, Abdulvahap G, Nizamettin D (2013) Investigation of the use of ammonium acetate as an alternative lixiviant in the leaching of malachite ore. Chem Ind Chem Eng Quarterly 19(1):25-35. https://doi.org/10.2298/ CICEQ120113039K

Baba AA, Adekola FA (2012) A study of dissolution kinetics of a Nigerian galena ore in hydrochloric acid, J Saudi Chem Society, 16: 377 - 389. Doi.org/ https://doi.org/10.1016/j.jscs.2011.02.005

Baba AA, Ghosh MK, Pradhan SR, Rao DS, Baral A, Adekola FA (2014)

Characterization and kinetic study on ammonia leaching of complex copper ore. Trans Nonferrous Met Soc China 24:1587-1595. https://doi.org/10.1016/ s1003-6326(14)63229-5

Baioumy HM, Khedr MZ, Ahmed AH (2013) Mineralogy, geo-chemistry and origin of $\mathrm{Mn}$ in high Mn iron ores, Bahariya Oasis Egypt, Ore Geo Review, 53: 63 76 https://doi.org/10.1016/j.oregeorev.2012.12.009

Chen G, Wang J, Xiaohui W, Shi-Li Z, Du H, Zhang Y (2013) An investigation on kinetics of chromium dissolution from Philippine chromite ore at high pressure in $\mathrm{KOH}$ sub-molten salt solution, Hydrometall, 139: 46 - 53, https://doi.org/10.1016/j.hydromet.2013.07.004 
Das AD, Koc E, Yazici YE, Deveci H (2015) Treatment of copper rich gold ore by cyanide leaching ammonia pretreatment and ammoniacal cyanide leaching. Trans Nonferrous Met Soc China 25:597-607. https://doi.org/10.1016/s10036326(15)63642-1

Elibol M (2002) Response surface methodology approach for inclusion of perfluorocarbon in acintinorhodin fermentation medium. Proc Biochem 38: $667-673$

Ferdowsi A, Yoozbashizadeh H (2017) Process optimization and kinetics for leaching of cerium, lanthanum, and neodymium elements from iron ore waste apatite by nitric acid. Trans Nonferrous Met Soc China 27:420-428. https://doi.org/10.1016/s1003-6326(17)60048-7

Jianrong X, Hong Z, Shuai W, Changxin L, Jinzhong L, Fangfang W (2016) Kinetics of reduction leaching of manganese dioxide ore with phytolacca Americana in sulfuric acid solution, J Saudi Chem Soc, 20: 437 - 442 https://doi.org/10. 1016/j.jscs.2014.09.011

Kitanovic S, Milenovic D, Veeljkovic VB (2008) Empirical kinetic models for the resinoid extraction from aerial parts of Saint John's Wort (hypericum perforatum L). J Biochem Eng 41:1-11

Kokes H, Moracali MM, Acma E (2014) Dissolution of copper and iron from malachite ore and precipitation of copper sulfate pentahydrate by chemical process, Eng Sci Technol Int J, 17: 39 - 44 https://doi.org/10.1016/j.jestch. 2014.03.002

Liddell KC (2005) Shrinking core model in hydrometallurgy - what student are being told about the pseudo-steady approximation. Hydrometall 79:62-68

Liu Y, Lin Q, Li L, Fu J, Zhu Z, Wang C, Qian D (2014) Study on the hydrometallurgy process and kinetics of manganese extraction from lowgrade manganese carbonate ores. Inter J Mining Sci Technol 24:567-571. https://doi.org/10.1016/j.jimst.2014.05.022

Madakkaruppan, V., Anitha P, Sreenivas T, Giri N, Sarbajna, C (2016) Influence of microwave on the leaching kinetics of uraninite from a low grade ore in dilute sulfuric acid, J Hazard Mater, 313: 9 - 17 https://doi.org/10.1016/j. jhazmat.2016.03.050

Madakkaruppan V, Anitha P, Sreenivas T, Shiv-kumar, K (2015) Leaching kinetics of uranium from a quartz-chlorite-biotite rich low-grade Indian ore, J Radio Anal Nuclear Chemistry, 303: 1793 - 1801 https://doi.org/10.1007/s10967-0143760-3

Madejova J, Komadel P (2001) Baseline studies for the clay mineral society: infrared methods. Clays Clay Miner 49:410-432

Manoj B, Kunjomana AG (2011) Analytical study of two different ranked coals using UV-VIS-NIR spectroscopy. J Miner Mater Characterization Eng 10:905-911

Nadeem R, Zafar IZ, Muhammad NH (2014) Utilization of formic acid solution in leaching kinetics of natural magnesite ore, Hydrometall, 149: 183 - 188 https://doi.org/10.1016/j.hydromet.2014.08.008

Ohale PE, Uzoh CF, Onukwuli, OD (2017) Optimal factor evaluation for the dissolution of alumina from Azaraegbelu clay in acid solution using RSM and ANN comparative analysis, South Africa J Chem Eng, 24: 43-54 https://doi. org/10.1016/j.sajce.2017.06.03

Olvera-venegas PN, Hernandez Cruz LE, Lapidus GT (2017) Leaching of iron oxide from kaolin: synergistic effect of citrate-thiosulfate and kinetic analysis. Hydrometall 171:16-26. https://doi.org/10.1016/.hydromet.2017.03.015

Seyed MSG, Azizi A (2018) Alkaline leaching of Lead and Zinc by sodium hydroxide: kinetics modeling, J Mater Res and Technol, 7: 118 - 125 https://doi.org/10.1016/j.jmrt.2017.03.005

Yi S, Xiao-Yi S, Yu-chun Z (2014) Thermodynamics and kinetics of extracting zinc from zinc oxide by ammonium sulfate roasting method. Inter J Miner Metall Mater 22(5):467. https://doi.org/10.1007/s12613-015-1095-x

Zhang Z, Peng J, Srivasakannanni C, Zhang Z, Zhang L, Fernandez Y, Menendez JA (2010) Leaching zinc from spent catalyst: process optimization using response surface methodology. J Hazard Mater 176:1113-1117

\section{Publisher's Note}

Springer Nature remains neutral with regard to jurisdictional claims in published maps and institutional affiliations. 